\title{
Apuntes metodológicos en torno a la historia y la antropología de la violencia
}

\author{
Methodological Notes on the History \\ and Anthropology of Violence
}

Los textos que conforman la primera parte de este número son el resultado de las reflexiones que mantuvimos durante el curso Historia y antropología de la violencia: reflexiones metodológicas en el Programa de Posgrado en Estudios Mesoamericanos, Universidad Nacional Autónoma de México (UNAM), entre agosto y noviembre de 2018. El objetivo general de este curso, como el nombre lo indica, fue examinar las herramientas teóricas y metodológicas utilizadas en casos de estudio dedicados a la violencia desde una perspectiva histórica y antropológica. La finalidad fue construir un campo de posibilidad para imaginar nuevas metodologías por dos motivos.

Primero, por la preocupación compartida ante la intensificación de la violencia articulada con el Estado mexicano en las primeras dos décadas del siglo xxi. Durante este periodo asistimos al incremento de las desapariciones forzadas - como la de los 43 normalistas de la Normal Raúl Isidro Burgos y las 36265 personas desaparecidas en el país $-{ }^{1}$ y fuertes operativos policiacos en contra de poblaciones civiles - tal como el caso de Nochixtlán, Oaxaca, en junio de 2016-. 2018 fue el año más violento en la historia reciente del país, con 33341 homicidios dolosos, según datos del Semáforo Delictivo Nacional. ${ }^{2}$

La urgencia de reconocer la violencia como un factor constitutivo de la investigación contemporánea de las humanidades y de las ciencias sociales también motivó la creación de este curso. Distintos grupos y redes han documentado, discutido y reflexionado sobre este problema. En la UNAM,

${ }^{1}$ Secretariado Ejecutivo del Sistema Nacional de Seguridad Pública, "Registro Nacional de Datos de Personas Extraviadas o Desaparecidas (RNPED)”, Acciones y Programas, acceso el 31 de mayo de 2018, https://www.gob.mx/sesnsp/acciones-y-programas/registro-nacional-de-datos-de-personas-extraviadas-o-desaparecidas-rnped.

${ }^{2}$ Secretariado Ejecutivo del Sistema Nacional de Seguridad Pública, "Víctimas de Delitos del Fuero común 2018. Instrumento para el Registro, Clasificación y Reporte de Delitos y las Víctimas CNSP/38/15", acceso el 25 de enero de 2019, http://secretariadoejecutivo.gob. $\mathrm{mx} /$ docs/pdfs/nueva-metodologia/CNSP-V\%C3\%ADctimas-2018_dic18.pdf. 
destaca la labor del seminario "Economía Política de la Violencia", ${ }^{3}$ así como el trabajo impulsado en el Instituto de Investigaciones Jurídicas para articular la investigación académica con defensores de derechos humanos y población civil. ${ }^{4}$ Destaca también el diplomado "Atención a víctimas de violencia y catástrofes", dirigido por la Universidad Iberoamericana, el Centro de Derechos Humanos Miguel Agustín Pro Juárez y el Museo Memoria y Tolerancia. Los organismos de Derechos Humanos ${ }^{5}$-Centro Prodh, ${ }^{6}$ el Centro de Derechos Humanos de la Montaña Tlachinollan $-{ }^{7}$ producen datos fundamentales sobre la violencia en el país. El periodismo es otra fuente de información relevante. Éste es el caso del trabajo M. Turati y J. Gibler, ${ }^{8}$ cuyas obras forman parte de un conjunto de publicaciones periodísticas que han transitado de la narración y la documentación de la guerra contra el narcotráfico al análisis cuidadoso de los actos de violencia.

En el curso Historia y antropología de la violencia: reflexiones metodológicas nos congregamos antropólogos, historiadores, periodistas, antropólo-

${ }^{3}$ Instituto de Investigaciones Económicas de la Universidad Nacional Autónoma de México, "Seminario Economía política de la violencia", Observatorio Latinoamaericano de Geopolítica (OLAG), acceso el 18 de noviembre de 2018, http://geopolitica.iiec.unam.mx/ node/180.

${ }^{4}$ Instituto de Investigaciones Jurídicas de la Universidad Nacional Autónoma de México, "Encuentro Académico sobre Prevención de la violencia armada y delitos relacionados con armas de fuego", Actividades académicas, acceso el 20 de octubre de 2018, https://www. juridicas.unam.mx/actividades-academicas/1582-la-investigacion-en-contextos-de-violencia; Instituto de Investigaciones Jurídicas de la Universidad Nacional Autónoma de México, "La investigación en contextos de violencia", Actividades académicas, acceso el 20 de octubre de 2018, https://www.juridicas.unam.mx/actividades-academicas/1907-encuentro-academico-sobre-prevencion-de-la-violencia-armada-y-delitos-relacionados-con-armas-de-fuego.

${ }^{5}$ Véase el informe anual del Centro de Derechos Humanos de la Montaña Tlachinollan, Montaña. Manantial de la resistencia, torbellino de esperanza. Informe de actividades julio de 2017-agosto de 2018 (México: MacArthur Foundation, 2018).

${ }^{6}$ Consúltese centroprodh.org.mx.

${ }^{7}$ Consúltese tlachinollan.org.

${ }^{8}$ John Gibler, Morir en México (México: Sur+, 2012); Marcela Turati, Fuego cruzado, las víctimas atrapadas en la guerra del narco (México: Grijalbo, 2011). Cabe señalar que muchos de los trabajos escritos y visuales elaborados en los últimos años fueron realizados de forma paralela a las indagaciones hechas por el Grupo Interdisciplinario de Expertas y Expertos Independientes (GIEI), el cual desde el año 2015 hizo una investigación con el objetivo de encontrar a los 43 normalistas de Ayotzinapa. Consúltese Grupo Interdisciplinario de Expertas y Expertos Independientes, Informe Ayotzinapa I. Investigación y primeras conclusiones de las desapariciones y homicidios de los normalistas de Ayotzinapa (México: GIEI, 2015); Grupo Interdisciplinario de Expertas y Expertos Independientes, Informe Ayotzinapa II. Avances y nuevas conclusiones sobre la investigación (México: GIEI, 2016). Véase en línea http://centroprodh.org.mx/GIEI/?cat=6. 
gos físicos, filósofos y filólogos. Hecho que corroboró la relevancia y la necesidad de construir espacios caracterizados por la multidisciplina para debatir en torno a la violencia. En conjunto formulamos las siguientes cuestiones: ¿cómo los contextos de violencia impactan la producción de las herramientas analíticas para describir y analizar fenómenos contemporáneos?, ¿qué posición de enunciación ocupamos los académicos frente a la violencia que enmarca nuestros casos y espacios de estudio?, ¿qué dispositivos teóricos y metodológicos aportarían a la problematización de esa violencia? Los artículos que conforman este número son algunas de las respuestas que imaginamos. Sumado a esto, algunos de ellos son el resultado del diálogo entablado con los colegas que participaron en la mesa de debate dedicada a la Producción de conocimiento en contexto de violencia en el marco del XIX Coloquio de Doctorandos de dicho Programa de Posgrado, celebrado en Ciudad Universitaria en octubre de 2018.

En esta presentación exponemos las guías generales de nuestro diálogo y las reflexiones creadas conjuntamente. Finalmente, esperamos sumarnos a la muliplicidad de espacios y de perspectivas necesarios para visibilizar desde el ámbito académico el creciente contexto de violencia en México.

Metodologías para abordar la violencia

Ante la amplitud de la temática a la que nos enfrentamos, el campo de análisis que sirvió como referente para nuestras discusiones fue la violencia articulada con el Estado nación de los siglos XIX, XX y XXI. Después de revisar las propuestas de algunos autores clásicos, tales como F. Engels, ${ }^{9} \mathrm{~W}$. Benjamin, ${ }^{10} \mathrm{M}$. Weber, ${ }^{11} \mathrm{~F}$. Fanon ${ }^{12}$ y H. Arendt, ${ }^{13}$ advertimos que las conceptualizaciones instrumentales de la violencia - entendida como un medio o como un fin y definida por cualidades creativas y productoras de sociabilidad- justificaban la instauración de un "contrato social de carácter estatal" en tanto destino natural de toda sociedad.

${ }^{9}$ Federico Engels, Obras filosóficas (México: Fondo de Cultura Económica, 1986).

${ }^{10}$ Walter Benjamin, Conceptos de filosofía de la historia (Buenos Aires: Caronte, 2009).

${ }^{11}$ Max Weber, El político y el científico (Madrid: Alianza Editorial, 1979).

${ }^{12}$ Frantz Fanon, Los condenados de la tierra (México: Fondo de Cultura Económica, 1961).

${ }^{13}$ Hanna Arendt, Sobre la violencia (Madrid: Alianza, 2006). 
Con base en una lectura crítica de estas propuestas filosóficas y políticas definimos como punto de partida: ir más allá de la figura, de la perspectiva y del punto de enunciación del Estado. A partir de las apuestas de P. Clastres, ${ }^{14}$ D. Graeber ${ }^{15}$ y R. Sztutman ${ }^{16}$ definimos el Estado como una fuerza coercitiva de homogeneización que, al sobreponerse a las fuerzas anti-estatales, adquirió la forma administrativa denominada Estado nación. De tal modo, el Estado era un conjunto de dominios que imponía las condiciones de producción de aquello que podía ser definido como real y como posible, incluida la base territorial - sobre la exploración de los imposibles epistemológicos y ontológicos, véase M. Blasser y M. de la Cadena- ${ }^{17}$ En este marco, apuntamos hacia tres objetivos metodológicos. Primero, el estudio del proceso de construcción de territorios y de personas como la condición necesaria para la permanente constitución de los Estados nación. Segundo, la comprensión de la articulación —o, en términos de A. Tsing, ${ }^{18}$ de los puntos de fricción- entre las escalas comprometidas en dichos procesos. Tercero, la revisión crítica del punto de enunciación de los autores en las narrativas académicas.

La construcción de personas y de territorios

La lectura de algunos acercamientos filosóficos y antropológicos en torno al genocidio ${ }^{19}$ fue reveladora para percatarnos de que los hechos de violen-

${ }^{14}$ Pierre Clastres, La sociedad contra el Estado (Barcelona: Monte Ávila Editores, 1978).

${ }^{15}$ David Graeber, Fragmentos de antropología anarquista (Bilbao: Virus editorial, 2008).

${ }^{16}$ Renato Sztutman, O Profeta e o Principal (São Paulo: Universidad de São Paulo (EDUSP), Fundación de Apoyo a la Investigación del Estado de São Paulo (FAPESP por sus siglas en portugués), 2012).

${ }^{17}$ Mario Blasser y Marisol de la Cadena, "Introduction”, en World Anthropologies Network (WAN). Red de Antropologías del Mundo (RAM), n. 4 (enero 2009).

${ }_{18}$ Anna Lowenhaupt Tsing, The Mushrom at the End of the World. On the Possibility of Life in Capitalist Ruins (Princeton: Princeton University Press, 2015).

${ }^{19}$ Desde 1948, la definición del delito de genocidio de la Convención para la Prevención y la Sanción del Delito de Genocidio y del Estatuto de Roma de la Corte Penal Internacional engloba las siguiente acciones: la matanza de miembros de un grupo, las lesiones graves a la integridad física o mental de estas personas, el sometimiento intencional de un grupo a condiciones de existencia que hayan acarreado su destrucción física, total o parcial, las medidas destinadas a impedir nacimientos en el seno del grupo y el traslado por la fuerza de niños de un grupo a otro. En México, por su parte, el delito de genocidio fue incorporado al Código Penal Federal a principios del año 1967 y comprende la destrucción "total o parcialmente a uno o más grupos nacionales o de carácter étnico, racial o religioso, perpetrase por 
cia asociados con el Estado nación eran el resultado de un continuum mayor -sugerimos consultar a N. Scheper-Huges ${ }^{20}$ y el libro Disturbing Remains: Memory, History, and Crisis in the Twentieth Century-.$^{21}$ Como consecuencia, advertimos que la "violencia aceptable" o los "crímenes del tiempo de paz" 22 han constituido los pilares de aquellos eventos o fenómenos que son reconocibles como violentos. Y que la violencia que nos interesaba comprender no era un acto volitivo ni el producto de acciones individuales. Un ejemplo es el trabajo periodístico de J. Gibler, quien analiza el narcotráfico como una economía de guerra articulada con el mercado global. ${ }^{23}$

Las reflexiones de J. Jing ${ }^{24}$ y de N. Scheper-Huges, ${ }^{25}$ sobre los genocidios en China (1959-1991) y en el nordeste de Brasil durante la dictadura militar (1964-1985), son representativas de cómo la violencia vinculada con el Estado nación pertenece a un continuum de violencias "menores" o "cotidianas" conformado, por ejemplo, por las ideas y las acciones colectivas sobre las "muertes aceptables". En ambos estudios, los autores destacan cómo los Estados han generado las condiciones necesarias -económicas, territoriales, poblacionales, políticas, religiosas, etcétera- para promover las conductas, coercitivas o prescriptivas que han producido personas y colectivos adecuados para conformar una nación, tales como obreros, soldados de la revolución, ciudadanos, productores y consumidores, etcétera. Simultáneamente, estas conductas normativas han definido a las personas que serían potencialmente el blanco de la violencia colectiva y, por tanto, de una muerte aceptable, tales como los pobres, los niños de la calle, las mujeres, los indígenas, etcétera. El incremento de la pobreza mundial ana-

cualquier medio, delitos contra la vida de miembros de aquellos, o impusiese la esterilización masiva con el fin de impedir la reproducción del grupo". También contempla los ataques a la integridad corporal, salud y aquellas acciones, cuyo propósito "someta intencionalmente al grupo a condiciones de existencia que hayan de acarrear su destrucción física, total o parcial”. Cámara de Diputados del H. Congreso de la Unión, “Código Penal Federal”, acceso el 25 de octubre de 2020, http://www.diputados.gob.mx/LeyesBiblio/pdf/9_051118.pdf.

${ }^{20}$ Nancy Scheper-Huges, “A Genealogy of Genocide”, Modern Psychoanalysis, v. 28, n. 2 (2003): 167-197.

${ }^{21}$ Michael S. Roth y Charles G. Salas, Disturbing Remains. Memory, History, and Crisis in the Twentieth Century (Los Angeles: The Getty Research Institute, 2011).

${ }^{22}$ Scheper-Huges, "A Genealogy of Genocide".

${ }^{23}$ Gibler, Morir en México..., 30.

${ }^{24}$ Jung Jing, "Male Ancestors and Female Deities. Finding Memories Trauma in a Chinese Village", en Disturbing Remains. Memory, History, and Crisis in the Twentieth Century, eds. Michael S. Roth y Charles G. Salas (Los Angeles: The Getty Research Institute, 2001).

${ }^{25}$ Scheper-Huges, "A Genealogy of Genocide". 
lizado por A. Nandy ilustra este punto. ${ }^{26}$ Para este autor, la pobreza es una afirmación del despojo de las formas de vida alternas, así como del proceso de institucionalización y normalización de la violencia en un régimen colonial. En América Latina, una manifestación de la producción de personas es aquello que F. Navarrete ${ }^{27}$ ha definido como ciudadanía étnica jerarquizada, es decir, aquella que ha sido prefijada a partir de la cultura y la identidad de los grupos euroamericanos y que ha fungido como una técnica de inclusión condicionada bajo la forma de una ciudadanía recortada y de segunda clase - véanse S. Rivera Cusicanqui ${ }^{28}$ y J. A. Kelly Luciani ${ }^{29}$ para los casos de Bolivia y Venezuela respectivamente-.

Por último, los materiales de J. Jing ${ }^{30}$ y de N. Scheper-Huges ${ }^{31}$ ejemplifican cómo la producción de personas se vincula directamente con la creación y la transformación del territorio. En el caso de la China comunista, la construcción de presas hidroeléctricas en la década de 1950 y el desplazamiento poblacional fueron piezas clave para modificar la relación de las personas con sus ancestros y, en consecuencia, con la natalidad. El trabajo de J. C. Scott, ${ }^{32}$ dedicado al estudio de la ocupación comercial y el reordenamiento del territorio en el sureste de Asia, también ilustra cómo la organización centralizada del territorio fue un mecanismo para redefinir a los actores y sus relaciones durante el Antiguo Régimen. Siguiendo a A. Mbembe, estas formas de territorialización han generado "líneas de demarcación y de jerarquías, de zonas y enclaves; el cuestionamiento de la propiedad; la clasificación de personas según diferentes categorías; la extracción de recursos y, finalmente, la producción de una amplia reserva de imaginarios culturales". ${ }^{33}$

${ }^{26}$ Ashis Nandy, Imágenes del Estado. Cultura, violencia y desarrollo (México: Fondo de Cultura Económica, 2011).

${ }^{27}$ Federico Navarrete, “¿Qué significa ser indio en el siglo XIX?”, en Los indígenas en la Independencia y en la Revolución Mexicana, coords. Miguel León-Portilla y Alicia Mayer (México: Universidad Nacional Autónoma de México, 2015), 176.

${ }^{28}$ Silvia Rivera Cusicanqui, Ch’ixinakax utxima. Una reflexión sobre prácticas y discursos descolonizadores (Buenos Aires: Tinta Limón, 2010), 53-73.

${ }^{29}$ José Antonio Kelly Luciani, Sobre a antimestiçagem (Florianópolis: Cultura e Barbárie, 2016).

${ }^{30}$ Jing, "Male Ancestors...".

${ }^{31}$ Scheper-Huges, "A Genealogy of Genocide".

${ }^{32}$ James Scott, The Art of not being governed. An anarchist history of uplands southeast Asia (Connecticut: Yale University Press, 2012).

${ }^{33}$ Achille Mbembe, Necropolítica (Madrid: Melusina, 2011), 43. 
A través de estas reflexiones planteamos que los hechos de violencia reconocibles en el México del siglo xx y del siglo xxi, tales como la desaparición de personas, los asesinatos numerarios, los etnocidios, los feminicidios, los ecocidios, etcétera, son el resultado de un largo y persistente continuum de violencia, así como de nuestra propia construcción como personas, como ciudadanos y como miembros de un Estado nación. En este marco, concluimos que dos posibles líneas de estudio para dar cuenta de la violencia en México consistirían en: a) indagar el proceso de construcción del territorio mexicano y del ciudadano mexicano - véanse trabajos como el de F. Navarrete ${ }^{34}$ sobre el racismo y de Y. Aguilar ${ }^{35}$ sobre los efectos políticos en la definición de lo indígena-, y b) examinar las premisas históricas y sociales de los marcos legislativos con el fin de identificar los principios que permiten violentar sistemáticamente a un pueblo y exterminarlo, en última instancia, explorar la idea bajo la cual la ciudadanía es una herramienta para la reproducción del ejercicio del poder estatal y, por tanto, creadora de minorías - para un análisis del concepto de ciudadanía multicultural y ciudadanía indígena, véase el trabajo de P. Garzón-. ${ }^{36}$ En México, por ejemplo, contamos con una legislación federal para tipificar el delito de genocidio, así como constituciones estatales que reconocen como delitos la discriminación y el etnocidio desde la década de 1990. En general, estas legislaciones son ambiguas ${ }^{37}$ y crean un espacio potencial para violentar a los pueblos, tal como documentó R. Velázquez ${ }^{38}$ entre los nahuas de San Pedro Tlanixco - para la comprensión del etnocidio de los pueblos amerindios en Amazonas sugerimos consultar a E. Viveiros de Castro (en este volumen), a P. Clastres $^{39}$ y R. Jaulin. ${ }^{40}$

${ }^{34}$ Federico Navarrete, Alfabeto del racismo mexicano (México: Ediciones Malpaso, 2017).

35 Yásnaya Elena Aguilar Gil, "Nosotros sin México, naciones indígenas y autonomía", Revista Nexos, acceso el 18 de mayo de 2018, https://cultura.nexos.com.mx/?p=15878.

${ }^{36}$ Pedro Garzón López, Del multiculturalismo a la colonialidad del poder (Madrid: Centro de Estudios Políticos y Constitucionales, 2016).

${ }^{37}$ Gobierno del Estado de Oaxaca, Procuraduría para la Defensa del Indígena, "Ley de derechos de los pueblos y comunidades indígenas del estado de Oaxaca”, acceso el 12 de junio de 2019, http://www.diputados.gob.mx/comisiones/asunindi/oaxregla.pdf.

38 Rogelio Velázquez, "Etnocidio contra nahuas de Tlanixco", Contralínea, acceso el 5 de julio de 2011, http://www.contralinea.com.mx/archivo-revista/2011/07/05/etnocidio-contra-nahuas-de-tlanixco/.

${ }^{39}$ Pierre Clastres, Arqueología de la violencia (México: Fondo de Cultura Económica, 2004).

${ }^{40}$ Robert Jaulin, La paix blanche. Introduction à l'ethnocide (París: Union Générale d'Éditions, 1974). 
Escalas, historia y puntos de enunciación

En esta línea de pensamiento, examinamos los procedimientos para construir personas y territorios, para administrar recursos políticos y económicos en el Antiguo Régimen y durante su transformación en el siglo XIX. Como resultado, señalamos la necesidad de identificar y de analizar las escalas vinculadas con la violencia, así como la urgencia de revisar críticamente el punto de enunciación del discurso académico.

Los trabajos de J. D. Weber ${ }^{41}$ y de J. Tutino ${ }^{42}$-dedicados respectivamente al estudio de la reformulación de la política de la Corona española hacia los indígenas no sometidos en el siglo XVIII y al análisis del vínculo entre las comunidades del centro de México en el siglo XVIII- detallan cómo el comercio y la expansión económica fueron mecanismos para desarticular las formas de organización local. A diferencia de los Estados modernos, éste fue apenas un medio de producción de sociabilidad y no el objetivo final. Aun así, la revisión de estos materiales confirmó la necesidad de analizar la conexión entre escalas y dominios diversos. Por ejemplo, al considerar la interacción entre personas concretas, J. Tutino destacó la relevancia de incluir en el análisis la configuración y el fortalecimiento de un sistema patriarcal.

La lectura de estas obras nos acercó a dos escalas espaciales del Antiguo Régimen: una de carácter local y otra continental. Con base en ellas, observamos las características del ejercicio de la violencia promovidas por el Estado monárquico e identificamos algunas de sus continuidades en el Estado moderno en América Latina, especialmente en el México del siglo XIX. Por ejemplo, la política imperial de la monarquía ibérica de la segunda mitad del siglo XVIII recuperó tradiciones de pacificación como la guerra, la ocupación del territorio - a través de los presidios y fortalezas- y el establecimiento de misiones en los confines. Estos hechos implicaron la invención de nuevas territorialidades y la producción de nuevas personas: por una parte, militares de frontera, y por otra, indios reducidos en misiones religiosas forzados a emprender los rudimentos de la fe católica y la vida en policía. ${ }^{43}$ Los textos analizados documentan formas distintas de

${ }^{41}$ Max Weber, El político y el científico.

${ }^{42}$ John Tutino, The Mexican Heartland. How Communities Shaped Capitalism, a Nation, and World History, 1500-2000 (New Jersey: Princeton University Press, 2017).

${ }^{43}$ Hacia 1737, el término policía definía al buen gobierno de las ciudades, pero también la "buena crianza y urbanidad, en el trato y costumbres", así como "aseo, limpieza [y] pulidez". 
violencia que, ejecutadas en diferentes escalas (relaciones de género, relaciones militares en la frontera), produjeron las relaciones económicas en el Antiguo Régimen.

Estas referencias fueron operativas para constrastarlas con el ejercicio de la violencia del Estado moderno y para percibir que algunos de los textos no abordaban abierta o detenidamente el tema de la violencia. Observamos entonces que las dificultades para problematizar la violencia posiblemente radicaban en la ausencia de marcos conceptuales y metodológicos, tal como fue señalado por R. Falcón ${ }^{44}$ o F. Navarrete, ${ }^{45}$ al documentar cómo en el siglo XIX la guerra era una herramienta de negociación y una práctica política. Como ambos autores señalan, algunas narrativas históricas han condenado las acciones de guerra ejecutadas por los campesinos - como en la denominada Guerra de Castas-, despolitizando y deslegitimando el uso de la violencia como una práctica política ordinaria y, con ello, sus motivos. A través de estas reflexiones, reconocimos la necesidad de revisar críticamente el punto de enunciación académica y, simultáneamente, percibimos una tendencia generalizada en la literatura histórica a normalizar las prácticas y los contextos de violencia de temporalidades distantes. Uno de los efectos de esta normalización diacrónica — misma que se radicaliza con la distancia temporal, es decir, entre más distante en el tiempo la violencia es menos reconocible- tiende a naturalizar, a minimizar y a invisibilizar actos de extrema violencia, tales como el genocidio, la tortura, el feminicidio, etcétera. A lo largo del curso, estas reflexiones decantaron en un cuestionamiento más amplio sobre las prácticas de conocimiento que participan en la reproducción de un tipo de violencia epistemológica. A manera de corolario, una de las preguntas que formulamos colectivamente fue ¿̇cómo construir desde nuestro oficio un punto de enunciación alterno al Estado y cómo hacerlo operativamente viable y válido?

Consúltese Real Academia Española, Diccionario de la lengua castellana, en que se explica el verdadero sentido de las voces, su naturaleza y calidad, con las phrases o modos de hablar, los proverbios o refranes, y otras cosas convenientes al uso de la lengua [Diccionario de autoridades], tomo v (Madrid: Imprenta de Real Academia Española, por los Herederos de Francisco del Hierro, 1737), 311-312.

${ }^{44}$ Romana Falcón, “Tiempos de guerra. Los usos de la violencia para ratificar y rectificar los derechos sobre los recursos naturales en el Estado de México, 1850-1870", en Pueblos en tiempos de guerra. La formación de la nación en México, Argentina y Brasil, 1800-1920, ed. Romana Falcón (México: El Colegio de México, 2017).

${ }^{45}$ Navarrete, "¿Qué significa ser indio...”. 
A. L. Barstow, por ejemplo, afirmó que en las narrativas históricas la violencia aparece en notas al pie y mediante eufemismos por el temor a "sensacionalizar" o hiper dramatizar las descripciones, o bien, de ser acusados de voyeristas. ${ }^{46}$ Para esta autora, éstas son expresiones de una censura que distorsiona nuestras narrativas históricas, generando olvido, construyendo el recuerdo de "algo más" y fortaleciendo la narrativa "de alguien más”. De ahí la relevancia de reconocer el punto de nuestra enunciación. Siguiendo a A. L. Barstow, el uso de ciertas etiquetas, como "cacería de brujas”, devela una posición política. De tal manera que no problematizar la violencia y no abordarla expresan una posición política también. En este marco, esta autora se cuestiona si la masacre ejecutada por paramilitares en Acteal, Chiapas, en 1997 debe ser narrada desde la perspectiva del gobierno mexicano, el perpetrador, o desde los sujetos violentados. La elección del punto o de los puntos de enunciación es fundamental para construir aquello que deseamos olvidar y aquello que recordaremos colectivamente. Esta reflexión también implica problematizar el tratamiento de las fuentes producidas en contextos de violencia y dotarlas de posiciones políticas e intencionalidades diversas. ${ }^{47}$

La crítica de D. Tedlock sobre el uso exclusivo de las fuentes producidas por ibéricos para comprender el pasado de los mayas ejemplifica esta cuestión. ${ }^{48}$ Para este autor, los ibéricos y los mayas se inscribieron mutuamente en sus historias, pero al utilizar un solo recurso aceptamos implícitamente las condiciones y las circunstancias de la producción de ese diálogo y, por tanto, la hegemonía de un punto de vista sobre el otro. Una expresión de esto es la premisa epistemológica bajo la cual la verdad puede ser separada de los métodos para obtenerla. Uno de los ejemplos presentandos por D. Tedlock es la reinterpretación de los textos elaborados por fray Diego de Landa, ya que paradójicamente éste es uno de los principales recursos para estudiar el pasado de los mayas. La propuesta de este autor para reinterpretar esta fuente es definir la práctica de la tortura como su contexto de producción —entendida como una extensión de la confesión sacramental ejecutada por la Inquisición-. De esta forma, D. Tedlock no pone en duda las fuentes europeas, sino el uso metodológico que los historiadores

${ }^{46}$ Anne Llewellyn Barstow, "Violence and Memory. The Politics of Denial”, Journal of the American Academy of Religion, v. 68, n. 3 (septiembre 2000): 595.

${ }^{47}$ Barstow, "Violence and Memory...", 595.

${ }^{48}$ Dennis Tedlock, "Torture in the Archives. Mayans Meet Europeans”, American Anthropologist, v. 95, n. 1 (marzo 1993): 139. 
contemporáneos hacemos de estas fuentes ${ }^{49}$ ¿Qué sucedería, por ejemplo, si las descripciones sobre los sacrificios registrados en ésta y en otras fuentes fuesen entendidos como producto de la tortura y no como documentos etnográficos análogos a los del presente? D. Tedlock sugiere reconocer que estos documentos registraron una convergencia de imaginaciones más que el recuento de eventos objetivos y que el contexto de producción de este diálogo asimétrico fue la violencia. Por tanto, este autor cuestiona la práctica de la escritura de la historia bajo la cual los perpetradores y sus actos de violencia se colocan entre paréntesis para identificar los datos sobre los mayas.

Esta propuesta resuena en el trabajo de R. Guha. ${ }^{50}$ Este autor retoma las fuentes producidas por gobiernos coloniales - y cualquier autoridadcon el fin de identificar en ellas otros puntos de enunciación y otras historias. La necesidad de multiplicar los puntos de enunciación radica en que, tal como advirtió J. Jing, ${ }^{51}$ es preciso resaltar o rescatar el sufrimiento colectivo que ha sido constitutivo o que ha sido una condición de los procesos de modernización progresista estatales; y en que, tal como señaló E. Viveiros de Castro (en este volumen), las condiciones de felicidad no pueden ser definidas por terceros, ya que éstas, como la producción de la memoria, son un acto de auto-definición.

En conclusión, consideramos la necesidad de proponer metodologías (locales y particulares) para entender la relación entre las escalas comprometidas en los eventos o en los contextos de violencia que estudiamos. Y reconocer críticamente los puntos de enunciación en las narrativas que construimos.

A manera de presentación

El artículo titulado “'Mientras los generales duermen’: desobediencia militar y rebelión en Sierra Gorda durante el conflicto bélico entre México y los Estados Unidos, 1846-1849”, de Ulises Ramírez Casas, problematiza las nociones de conflicto, violencia e injusticia a través de una serie de fuentes documentales generadas a partir de la correspondencia entre militares, reclutas y fugitivos que mostraron su rechazo a la guerra entre dichos países.

\footnotetext{
49 Tedlock, “Torture in the Archives...", 142.

${ }^{50}$ Ranahit Guha, Las voces de la historia y otros estudios subalternos (Barcelona: Crítica, 2002).

${ }^{51}$ Jing, "Male Ancestors...”.
} 
El objetivo que guía el texto es la recreación de un contexto de violencia bélica que permite explicar cómo fue que diversos actores y sectores marginales interpretaron la guerra y cómo esa lectura de los hechos desembocó en una rebelión que buscó establecer alianzas con el ejército norteamericano. El autor sugiere observar en los procesos de conformación del Estado nación la principal causa de agravios directos y de violencia hacia las poblaciones, en especial el reclutamiento forzado y las contribuciones desmedidas. Finalmente, aporta una serie de herramientas analíticas y conceptuales para repensar la violencia armada durante la primera mitad del siglo XIX.

En el artículo elaborado por Juan Vicente Iborra Mallet, titulado "Los límites a las políticas de reconocimiento y el derecho a la consulta previa en Honduras. El caso garífuna", se presenta un análisis de larga duración sobre las formas de violencia ejercidas hacia los garífunas, tomando como ejes la esclavitud, la guerra, el desplazamiento y el despojo territorial. El artículo inicia en el siglo XVIII, durante la disputa geopolítica entre Gran Bretaña y Francia por el control de las Antillas Menores. Éste fue el escenario de una campaña bélica que tuvo como objetivo reducir y desplazar a los "caribes negros", no solamente por su apoyo a los franceses, sino por su forma de vida opuesta al sistema de plantaciones. Una vez lograda la expulsión de los "caribes negros" a manos de los ingleses, el autor nos guía a través del desplazamiento y de la ocupación de nuevos territorios, hoy conformados por varios Estados nacionales de Centroamérica. Como corolario, en el texto se analizan las implicaciones de la Ley de consulta libre, previa e informada, promovida por el Estado hondureño en el siglo xx, en especial el acaparamiento de tierras que puede calificarse como el motor de la "tercera expulsión".

"De violencia y estereotipos. Visiones en torno a la muerte suicida en poblaciones mayas yucatecas", elaborado por Mundo A. Ramírez Camacho, cuestiona que el suicidio en poblaciones mayas sea el resultado de una tradición cultural milenaria. Para historiadores, periodistas y funcionarios públicos del sector salud de la península existe una relación estrecha entre los altos índices de suicidios y una deidad prehispánica denominada Ixtab, reportada por fray Diego de Landa, uno de los personajes más controvertidos de la historia colonial temprana. El autor nos guía a través de un análisis de fuentes primarias escritas en el siglo XVI para mostrar cómo el uso del pasado normaliza la muerte entre los pueblos mayas contemporáneos de la península de Yucatán. 
A estos materiales se suma la traducción del texto titulado "Sobre la noción de etnocidio, con especial atención al caso brasileño (2016)", de Eduardo Viveiros de Castro, elaborada por Alejandro Fujigaki Lares y María Isabel Martínez Ramírez. Esta lectura fue una pieza clave para el examen colectivo de nuestro curso y, por tanto, para las reflexiones antes expuestas. Por ello, agradecemos que el autor aceptara sumar su texto a este proyecto. Además de ofrecer un análisis profundo de las nociones de genocidio y de etnocidio, este antropólogo brasileño enfatiza el papel de la legislación para promover o evitar estos eventos. Finalmente, ofrece un debate puntilloso sobre el problema en torno a la definición del indígena y de lo indígena, así como sobre aquello que enunciaba Eliane Brum en torno al Amazonas y a los pueblos indígenas: "Nada es más autoritario que decir a otro que no es lo que es" (2014). ${ }^{52}$ Finalmente, a este conjunto de reflexiones se incorpora la reseña del libro La otra esclavitud. Historia oculta del esclavismo indígena, escrito por Andrés Reséndez. ${ }^{53}$ En este texto María Isabel Martínez Ramírez describe los hilos conductores de la obra de Reséndez y establece un dialogo multidisciplinario, en el cual incluye una perspectiva antropológica y una perspectiva periodística, para problematizar las fomas de explotación contemporánea a la luz del rico panorama histórico sobre la esclavitud ofrecido por Reséndez.

María IsAbel Martínez

ULISES RAMÍREZ

\section{BiBLIOGRAFÍA}

Aguilar Gil, Yásnaya Elena. "Nosotros sin México, naciones indígenas y autonomía”, Revista Nexos, acceso el 18 de mayo de 2018, https://cultura.nexos.com. $\mathrm{mx} / \mathrm{p} \mathrm{p}=15878$.

Arendt, Hanna. Sobre la violencia. Madrid: Alianza Editorial, 2006.

Barstow, Anne Llewellyn. "Violence and Memory. The Politics of Denial", Journal of the American Academy of Religion, v. 68, n. 3 (septiembre 2000): 591-602.

52 Eliane Brum, "A ditadura que nao diz seu nome", Para que no se repita la historia, acceso el 1 de marzo de 2019, https://paraquenoserepitalahistoria.blogspot.com/2014/04/ la-dictadura-que-no-dice-su-nombre.html.

${ }^{53}$ Andrés Resédez, La otra esclavitud. Historia oculta del esclavismo indígena (México: Grano de Sal/Universidad Nacional Autónoma de México, Instituto de Investigaciones Históricas, 2019). 
Blaser, Mario, y Marisol de la Cadena. "Introduction.” World Anthropologies Network (WAN). Red de Antropologías del Mundo (RAM), n. 4 (enero 2009): 3-10.

Benjamin, Walter. Conceptos de filosofía de la historia, Buenos Aires: Caronte, 2009. Brum, Eliane. "A ditadura que nao diz seu nome", Para que no se repita la historia, acceso el 1 de marzo de 2019, https://paraquenoserepitalahistoria.blogspot. com/2014/04/la-dictadura-que-no-dice-su-nombre.html.

Cámara de Diputados del H. Congreso de la Unión. “Código Penal Federal”, Diputados, acceso el 25 de octubre de 2020, http://www.diputados.gob.mx/LeyesBiblio/pdf/9_051118.pdf.

Centro de Derechos Humanos de la Montaña Tlachinollan. Montaña. Manantial de la resistencia, torbellino de esperanza. Informe de actividades julio de 2017-agosto de 2018. México: MacArthur Foundation, 2018.

Clastres, Pierre. La sociedad contra el Estado. Barcelona: Monte Ávila Editores, 1978. Clastres, Pierre. Arqueología de la violencia. México: Fondo de Cultura Económica, 2004.

Engels, Federico. Obras filosóficas. México: Fondo de Cultura Económica, 1986.

Falcón, Romana. “Tiempos de guerra. Los usos de la violencia para ratificar y rectificar los derechos sobre los recursos naturales en el Estado de México, 18501870", en Pueblos en tiempos de guerra. La formación de la nación en México, Argentina y Brasil, 1800-1920, ed. Romana Falcón. México: El Colegio de México, 2017, 159-188.

Fanon, Frantz. Los condenados de la tierra. México: Fondo de Cultura Económica, 1961. Garzón López, Pedro. Del multiculturalismo a la colonialidad del poder. Madrid: Centro de Estudios Políticos y Constitucionales, 2016.

Gibler, John. Morir en México. México: Sur+, 2012.

Gobierno del Estado de Oaxaca, Procuraduría para la Defensa del Indígena. "Ley de derechos de los pueblos y comunidades indígenas del estado de Oaxaca”, Diputados, acceso el 12 de junio de 2019, http://www.diputados.gob.mx/comisiones/asunindi/oaxregla.pdf.

Graeber, David. Fragmentos de antropología anarquista. Bilbao: Virus editorial, 2008. Grupo Interdisciplinario de Expertas y Expertos Independientes. Informe Ayotzinapa I. Investigación y primeras conclusiones de las desapariciones y homicidios de los normalistas de Ayotzinapa. México: Grupo Interdisciplinario de Expertas y Expertos Independientes (GIEI), 2015.

Grupo Interdisciplinario de Expertas y Expertos Independientes. Informe Ayotzinapa II. Avances y nuevas conclusiones sobre la investigación. México: Grupo Interdisciplinario de Expertas y Expertos Independientes (GIEI), 2016.

Guha, Ranahit Guha. Las voces de la historia y otros estudios subalternos. Barcelona: Crítica, 2002. 
Jaulin, Robert. La paix blanche. Introduction à l'ethnocide. París: Union Générale d'éditions, 1974.

Jing, Jung. "Male Ancestors and Female Deities. Finding Memories Trauma in a Chinese Village", en Disturbing Remains. Memory, History, and Crisis in the Twentieth Century, eds. Michael S. Roth y Charles G. Salas, 207-230. Los Angeles: The Getty Research Institute, 2001.

Kelly Luciani, José Antonio. Sobre a antimestiçagem. Florianópolis: Cultura e Barbárie, 2016.

Mbembe, Achille. Necropolítica. Madrid: Melusina, 2011.

Nandy, Ashis. Imágenes del Estado. Cultura, violencia y desarrollo. México: Fondo de Cultura Económica, 2011.

Navarrete, Federico. “¿Qué significa ser indio en el siglo XIX?”, en Los indígenas en la Independencia y en la Revolución Mexicana, coords. Miguel León-Portilla y Alicia Mayer, 171-190. México: Universidad Nacional Autónoma de México, 2015.

Navarrete, Federico. Alfabeto del racismo mexicano. México: Malpaso, 2017.

Real Academia Española. Diccionario de la lengua castellana, en que se explica el verdadero sentido de las voces, su naturaleza y calidad, con las phrases o modos de hablar, los proverbios o refranes, y otras cosas convenientes al uso de la lengua [Diccionario de autoridades], tomo v. Madrid: Imprenta de Real Academia Española, por los Herederos de Francisco del Hierro, 1737.

Resédez, Andrés. La otra esclavitud. Historia oculta del esclavismo indígena, México: Grano de Sal/Universidad Nacional Autónoma de México, Instituto de Investigaciones Históricas, 2019.

Roth, Michael S., y Charles G. Salas. Disturbing Remains. Memory, History, and Crisis in the Twentieth Century. Los Angeles: The Getty Research Institute, 2011.

Rivera Cusicanqui, Silvia. Ch'ixinakax utxima. Una reflexión sobre prácticas y discursos descolonizadores. Buenos Aires: Tinta Limón, 2011.

Scheper-Hughes, Nancy. "A Genealogy of Genocide”, en Modern Psychoanalysis, v. 28, n. 2 (2003): 167-197.

Scott, James. The Art of not being governed. An anarchist history of uplands southeast Asia. Connecticut: Yale University Press, 2012.

Secretariado Ejecutivo del Sistema Nacional de Seguridad Pública. "Víctimas de Delitos del Fuero común 2018. Instrumento para el Registro, Clasificación y Reporte de Delitos y las Víctimas CNSP/38/15", Secretariado Ejecutivo, acceso el 25 de enero de 2019, http://secretariadoejecutivo.gob.mx/docs/pdfs/nueva-metodologia/CNSP-V\%C3\%ADctimas-2018_dic18.pdf.

Secretariado Ejecutivo del Sistema Nacional de Seguridad Pública. "Registro Nacional de Datos de Personas Extraviadas o Desaparecidas (RNPED)”, Acciones 
y Programas, acceso el 31 de mayo de 2018, https://www.gob.mx/sesnsp/acciones-y-programas/registro-nacional-de-datos-de-personas-extraviadas-o-desaparecidas-rnped.

Sztutman, Renato. O Profeta e o Principal. São Paulo: Universidad de São Paulo (EDUSP), Fundación de Apoyo a la Investigación del Estado de São Paulo (FAPESP), 2012. Tedlock, Dennis. "Torture in the Archives: Mayans Meet Europeans." American Anthropologist, v. 95, n. 1 (marzo 1993): 139-152.

Tsing, Anna Lowenhaupt. The Mushrom at the End of the World. On the Possibility of Life in Capitalist Ruins. Princeton: Princeton University Press, 2015.

Turati, Marcela. Fuego cruzado, las víctimas atrapadas en la guerra del narco. México: Grijalbo-Mondadori, 2011.

Tutino, John. The Mexican Heartland. How Communities Shaped Capitalism, a Nation, and World History, 1500-2000. New Jersey: Princeton University Press, 2017.

Velázquez, Rogelio. "Etnocidio contra nahuas de Tlanixco." Contralínea, acceso el 5 de julio de 2011, http://www.contralinea.com.mx/archivo-revista/2011/07/05/ etnocidio-contra-nahuas-de-tlanixco/.

Viveiros de Castro, Eduardo. Sobre a noção de etnocidio, com especial atenção oa caso brasileiro, (manuscrito) https://www.academia.edu/25782893/Sobre_a_ noção_de_etnoc\%C3\%ADdio_com_especial_atenção_ao_caso_brasileiro

Weber, Max. El político y el científico, Madrid: Alianza Editorial, 1979. 